\title{
Psicanálise, educação e subjetividades contemporâneas: articulações
}

\section{Psychoanalysis, education and contemporary subjectivities: articulations}

\begin{abstract}
Maria Regina Maciel, Professora Associada da Faculdade de Educação da UERJ, é graduada em Psicologia pela Universidade Santa Úrsula, com mestrado em Psicologia Clínica pela PUC-RJ e doutorado em Saúde Pública pela UERJ.
\end{abstract}

Contato: mreginamaciel@terra.com.br

\section{Resumo}

0 artigo articula psicanálise e educação. Acompanha os inícios desse processo, com Freud, que resultaram na abertura de uma área de interesse, atualmente consolidada. 0 texto trata também dos novos processos de subjetivação, a fim de pensar propostas de trabalho derivadas desse campo e desenvolvidas nas escolas hoje.

Palavras-chave: Psicanálise. Educação. Subjetividades contemporâneas.

\begin{abstract}
This paper addresses psychoanalysis and education. It observes the beginning of this process, with Freud, which resulted in the beginning of an area of interest, currently consolidated. This paper also addresses the contemporary processes of subjectivation, in order to find work proposals derived from this area, and currently developed in schools. Keywords: Psychoanalysis. Education. Contemporary subjectivity.
\end{abstract}

\section{Introdução}

As articulações entre psicanálise e educação têm uma história que começa com Freud e se estende até os textos atuais de 
psicanalistas e educadores. Esses entrelaçamentos, hoje, já constituem um campo, um conjunto de interlocutores consolidado.

No que concerne ao início desses enlaces, Sigmund Freud se debruçou sobre a transmissão de conhecimento levando em consideração o Inconsciente. Isso implica afirmar que algo sempre escapa à pretensão de controle consciente, por exemplo, de tudo o que aprendemos. Seus textos também fazem referência à transferência enquanto fenômeno que se passa não apenas entre paciente e terapeuta, mas que perpassa todas as relações humanas, inclusive a de professor-aluno. Da mesma maneira, ele escreve sobre o papel da educação como auxiliar da sublimação sexual.

Alguns de seus textos incidem sobre o tema da educação e dão pistas para a prática educacional. Em "Recomendações aos médicos que exercem a psicanálise" (FREUD, 1912) encontramos recomendações para que o educador não queira modificar os alunos à sua imagem, tomando para si a função de modelo. Em "Algumas reflexões sobre a psicologia escolar" (FREUD, 1914), o autor sugere preocuparmo-nos com o jeito com que ensinamos, mais do que com o que ensinamos. E em "Explicações, aplicações e orientações" (FREUD1932), alude à tentativa da "educação psicanalítica" de procurar um "ponto ótimo" que possibilite "proibição de pulsão" sem "doença neurótica". Podemos afirmar que predomina nas referências freudianas uma visão da educação como repressora das pulsões ou inibidoras do ego. Isto, apesar de suas indicações a respeito do "infantil" que, contrariamente ao desenvolvimento, escapa a essas funções e "cria o mundo".

Das repercussões dos textos freudianos que abordam a questão da educação, merece destaque o livro Freud: anti-pedagogo, de Catherine Millot (1987). Nele, a autora afirmava a impossibilidade de aplicar psicanálise à educação, na medida em que aquela poderia apenas transmitir ao educador uma ética, um modo de ver e de entender a prática educativa.

Essa radicalização da separação entre esses dois campos reverberou em autores brasileiros que, posteriormente, repensaram seus pontos de vista a fim de aproximar mais os campos. É o caso de Kupfer (2015), que inicialmente seguiu o que dizia o livro de Millot (1987), mas que chegou a admitir ser possível conceber uma educação orientada pela psicanálise. Propôs, assim, a "educação terapêutica" voltada, sobretudo, para crianças autistas e psicóticas. Esta seria um conjunto de práticas interdisciplinares de tratamento que visa à retomada do desenvolvimento g'lobal da criança. 
Influenciados pela leitura lacaniana de Freud, outros tantos trabalhos foram tecidos. É o caso de Mariotto (2009) e Aragão (2009), que entendem que o que se passa nas creches, por exemplo, incide sobre a constituição subjetiva da criança pequena. Podemos encontrar nesses autores uma concepção de creche como "terceiro". Neste caso, esses textos apontam para a função paterna e o complexo de Édipo. A tríade pai-mãe-bebê seria, de certa forma, o ponto de partida para a constituição de um sujeito do desejo. Com esse tipo de encaminhamento, encontramos esclarecimentos nos quais se afirma que os educadores de creches não são substitutos da função materna, embora exerçam a maternagem. Da mesma forma, a creche seria uma espécie de terceiro organizador nas relações entre crianças, pais e educadores.

Interessados nos enlaces entre esses dois campos - porém mais influenciados pela leitura winnicottiana dos textos freudianos -, outros textos também foram produzidos. Vale esclarecer que, para o psicanalista inglês (WINNICOTT, 1963), educação não é submissão e a escola pode possibilitar que a criança expanda seus próprios limites (WINNICOTT, 1936). Isso porque, nos seus escritos, o outro não vem em oposição, podendo, sim, ajudar a integrar ou dar forma ao ímpeto da criança. A educação, nesse caso, pode - se trabalhar, sobretudo, no "espaço transicional" - facilitar o crescimento do aluno que se encontra em relação de dependência/ independência com os outros.

Nesse mesmo diapasão, Loparic (2008) e Fulgencio (2008) evocam a noção de origem do ser a partir de certo acontecer maturacional. Nesse sentido, as noções winnicottianas de "continuidade do ser" e "tendência ao amadurecimento", que passa de um momento de "dependência absoluta" para uma "dependência relativa", apontam para o papel da escola e dos educadores na direção de cuidados "suficientemente bons".

Da mesma maneira, Maciel (2016), destaca o valor do holding do ambiente escolar. Este poderia aceitar a singularidade de cada criança, adaptando-se a suas necessidades e dando espaço ao brincar criativo. A autora sustenta a importância das experiências das trocas corporais entre bebê e seus cuidadores e lembra que as creches podem oferecer à primeira infância cuidados contínuos e a necessária estabilidade para um amadurecimento saudável. Nesse caso, a convivência com os outros pequenos e com os educadores pode permitir uma gradual convivência com a alteridade. Em termos mais práticos, propõe que o psicanalista circule por todos 
os espaços institucionais, disponibilizando um cuidado e uma escuta analítica.

Após essa introdução aos enlaces da psicanálise com a educação, julgamos necessário refletir sobre os processos de subjetivação contemporâneos. Acreditamos que mudanças ocorridas nesses últimos podem gerar transformações na intersecção entre os campos estudados.

\section{Processos de subjetivação contemporâneos}

Se na modernidade nos libertamos da servidão ante a autoridade divina, no mundo pós-moderno, com a perda das utopias, intensificou-se a sensação de desamparo. Não é a toa que, nos últimos anos, assistimos ao alargamento no número de casos de depressão, entre outros tantos sofrimentos típicos de nossa contemporaneidade.

Tomemos o que nos disse Ehrenberg (1998) quando debruçouse sobre as mutações da individualidade na virada do século XX para o XXI. 0 sociólogo francês mostra que, desde os anos 1970, a depressão - que ele chama de "patologia da liberdade", ligada a uma expressão da falta de tensão e de forças internas para responder às diversas demandas com que os indivíduos se veem confrontados - se torna o problema mental mais disseminado no mundo. Ele se pergunta: "Por que e como a depressão se impôs como nossa principal infelicidade íntima (EHRENBERG, 1998, p. 9), dando neste 'sujeito fatigado de ser si mesmo'"?

Seu intuito é combinar uma história cultural e uma história técnica da psiquiatria, pretendendo mostrar como a alteração no entendimento da psiquiatria sobre as depressões está ligada a uma mudança na experiência coletiva das pessoas que, primeiramente, se exprimiam tanto pelo assujeitamento disciplinar quanto pelo conflito, e que, agora, se veem às voltas com a questão da responsabilidade e da ação. Sendo assim, uma das hipóteses levantadas no livro é que a depressão nos instrui sobre nossa experiência atual porque é a patologia de uma sociedade na qual a norma não é mais fundada sobre a culpabilidade e a disciplina, mas sobre a responsabilidade e a iniciativa. 0 sujeito do conflito, próprio da neurose, é substituído pela dificuldade de se definir um sujeito. Este, no máximo, pode ser definido como sujeito insuficiente da depressão.

A transformação do modelo de entendimento da melancolia para a depressão "distímica" - e, por que não dizer, da transformação 
no número de pacientes com tais patologias - seria um efeito da passagem da sociedade disciplinar - na qual o indivíduo disciplinado era o indivíduo do conformismo e das ambições moderadas, que valorizava modelos coletivos de conduta, que tinha regras claras a serem seguidas - para a sociedade contemporânea - na qual o indivíduo é aquele que se deixa seduzir pela ideia de que tudo está ao seu alcance, desde que saiba reconhecer o seu desejo mais autêntico. Passa-se a mensagem de que tudo depende exclusivamente da criatividade e do empenho de cada um, o que faz crescer o sentimento de responsabilidade.

Ehrenberg levanta, então, a hipótese de que "o sucesso da depressão repousa sobre o declínio da referência ao conflito sobre o qual se construiu a noção de sujeito que o fim do século XIX nos legou". Acrescenta, ainda, que "a identificação das noções de conflito e de sujeito se faz com a invenção da "psiconeurose de defesa' por Freud" (idem, p. 16).

No modelo freudiano calcado na culpa, se o tornar-se adulto equivalia à angústia de se tornar si mesmo, no modelo atual da insuficiência predomina a "fadiga de ser si mesmo". No lugar da angústia, derivada do confronto com o interdito, o vazio depressivo. A angústia de ser quem se é, própria do homem emancipado do século XIX que se via às voltas com a transposição do interdito, se transforma no cansaço, na depressão, de ser quem se é: um ser que vive na questão do que é possível fazer e não na questão do que é permitido fazer. "É por esta razão que a insuficiência está para a pessoa contemporânea como o conflito estava para aquela da primeira metade do século XX" (EHRENBERG, 1998, p. 235).

Seguindo seus argumentos, o homem contemporâneo não se sente, por isso, um ser forte. Ao contrário, esse ser está cansado de sua soberania, a qual inclui um ideal extremamente exigente de autonomia da ação individual. A fadiga, aí gerada, esgota, esvazia e torna o indivíduo incapaz de agir, sendo uma patologia da responsabilidade, uma doença da insuficiência.

Ehrenberg conclui afirmando que seria inútil pleitear um retorno ao proibido ou reivindicar limites aos sujeitos que não os conhecem mais. Não se volta mais atrás. Segundo ele, devemos compreender que o desconhecido (o autor se refere às significações que ultrapassam e constituem o humano) em nós se transforma, e assim se deslocam custos e benefícios. Entende, então, que saímos dos dramas da culpa e da obediência para os dramas da responsabilidade e da ação. A partir das mudanças 
nas experiências coletivas das pessoas, a fadiga depressiva toma espaço sobre a angústia neurótica. Se, segundo Freud, o homem se tornava neurótico porque não podia suportar o grau de renúncia exigido pela sociedade, ele agora se torna deprimido porque deve suportar a ilusão de que tudo lhe é possível.

0 que disse Ehrenberg nos faz lembrar de Sennett (1998) quando este último referiu-se aos dias de hoje como aqueles em que assistimos ao fim da cultura pública e à crescente política da personalidade que gera um voltar-se para dentro. Segundo Sennett (1998), assim o eu é despojado da expressão de certos poderes criativos que todos os seres humanos possuem potencialmente. Ele chama isso de "poderes de jogo", que requerem um ambiente à distância do eu para sua realização. Essa sociedade, segundo ele, faz do indivíduo um ator privado de sua arte.

Sennett nos leva a fazer um confronto entre jogo e narcisismo. As forças do narcisismo, mobilizadas por nossa cultura, acabam por derrotar o poder de brincar que o ser humano tinha antes de crescer e de adentrar à "realidade". Nesse sentido, o narcisismo enfraquece a capacidade de jogo e apaga a linha divisória entre eu e outro. 0 que significa, para esse autor, que nada de novo, nada de "outro" adentra o eu. Podemos dizer que a cultura do narcisismo afasta os indivíduos dos poderes do jogo. Isto é, das brincadeiras expressivas e da aceitação tanto do outro quanto das regras compartilhadas.

\section{Novos laços entre psicanálise e educação}

Ao passarmos por questões relativas aos processos de subjetivação contemporâneos é possível afirmar que hoje a sensação de desamparo se intensificou. Como será que esse fato se reflete nas interações entre psicanálise e educação? A resposta parece estar nos laços entre irmãos que têm aparecido como projeto ético e político.

Lembremos de Kehl (2000) ao questionar o privilégio da noção de função paterna em psicanálise e propor o tema da "função fraterna". Ela se pergunta: será que toda coletividade está pedindo um Füher, conforme postulava Freud (1921)? A autora propõe, então, rever a noção de fratria, pretendendo examinar outros modos de operação do sujeito com os semelhantes, que não só a alienação.

Seus argumentos vão no sentido de afirmar que nem sempre o irmão precisa ser o intruso ou rival ao disputar o amor dos 
genitores. Não se poderiam estabelecer laços de solidariedade entre irmãos? Ainda segundo ela, poderíamos pensar constituições grupais em que as fratrias forneçam amparo. Isso, entretanto, buscando não cristalizá-las, pois, nesse caso, haveria o perigo de se transformarem em círculos fechados de proteção imaginária nos quais a alteridade poderia ser rechaçada.

Numa perspectiva semelhante, Birman (2006), mais do que "função fraterna", prefere usar o termo fraternidade. Faz isso ao afirmar que essa problemática exige, teoricamente, que se considere a presença da economia libidinal nos laços sociais. Ele acrescenta ser preciso apreender a fraternidade de fora do registro da rivalidade e depreender dela uma positividade.

Esse último autor afirma que, sem nostalgia do pai, trata-se de erotizar e sublimar as diversas formas de subjetivação. Assim, o psiquismo, na medida do possível, se defrontaria criativamente com a sua condição de desamparo. Fraternidade se projetando agora não como defesa contra desamparo, numa espécie de servidão voluntária diante de um pai morto que precisamos restaurar, porém fraternidade a partir do reconhecimento desse desamparo que afirma as incertezas.

Reflexos dessa fraternidade - que não é defesa contra desamparo e que afirma as incertezas - podem ser percebidos no campo da intersecção entre psicanálise e educação. Afirmamos isso ao notar transformações na forma como alguns psicanalistas têm atuado, se posicionando de maneira mais horizontalizada no seu fazer psicanalítico em espaços escolares.

É possível dizer que anos atrás havia uma tendência de oferecer serviços clínicos, tanto dentro quanto fora das escolas, em uma espécie de consultório estendido. Gradativamente os psicanalistas começam a valorizar o próprio contexto escolar, o que acabou acarretando uma maior circulação no interior, no cotidiano, das escolas. Por fim, temos assistido a inúmeras e crescentes propostas de se trabalhar com grupos (de professores, de pais, de crianças), a fim de escutar e implicar os vários sujeitos envolvidos nas atividades sugeridas.

Ilustrando o que acabamos de afirmar, como propostas mais recentes de trabalhos práticos grupais podemos nos referir ao trabalho de Outeiral (2005) ao propor grupos com alunos, pais e professores cujas dinâmicas ficam próximas, segundo ele, dos "grupos operativos". Podemos também nos reportar, neste caso a partir da perspectiva lacaniana, a trabalhos que propõem dar 
voz aos educadores, sujeitos da investigação, nas Conversações (Miranda \& Santiago, 2010). Estas se referem a um dispositivo grupal da psicanálise, criado por Jacques-Alain Miller, que propõe uma espécie de "associação livre coletivizada" em que o que um diz evoca no outro o seu dizer. Visa pensar, por exemplo, o próprio desejo do educador diante de seu trabalho.

\section{A título de conclusão ou pensando as escolas hoje}

Sabemos que, na modernidade, o homem se libertou da servidão ante a autoridade divina. Nesse caso, vimos que o risco é a "cultura do narcisismo" em sua busca de um eu autossuficiente. Já no mundo pós-moderno, com a perda das utopias, intensificaramse tanto o desamparo quanto o risco das depressões, entre outros sofrimentos contemporâneos. É aí que penso que a noção de fraternidade (e não a função paterna) pode ser privilegiada. Fraternidade que confira positividade à precariedade de todos nós.

Diante das subjetividades contemporâneas, alguns psicanalistas têm proposto trabalhos em grupo com os atores escolares. Ao darem voz a esses sujeitos, trazem ao centro dos debates os que estão, muitas vezes, à margem dos processos decisórios. Mas, além disso, essas propostas, por meio do brincar criativo e da convivência com as diferenças, podem servir de espaços na contramão da apatia e da "fadiga de ser si mesmo", conforme vimos no item anterior.

A psicanálise nos ensina que sem uma base de criatividade e confiança nos submetemos à realidade, ou seja, ao que está fora de nós e já estabelecido. Por outro lado, sabemos que as escolas são lugares de reprodução do instituído, nos quais questões como as desigualdades entre as classes sociais tendem a se repetir. Afinal, as escolas, por si só, não transformam a sociedade, da qual são apenas um elemento. Elas dependem de políticas públicas efetivas e concretas do Estado.

Nas instituições escolares, todavia, também há lugar para o novo - como sabemos ter sido o caso, por exemplo, das escolas públicas ocupadas pelos jovens secundaristas, nos últimos anos, em vários estados brasileiros, e que tanto nos ensinaram sobre suas formas mais horizontalizadas de fazer política. Tive oportunidade de visitar duas escolas ocupadas. E, nesses estabelecimentos, não vi submissão. Então, algo ali se passou que permitiu o novo advir. 
A título de ilustração - já que este artigo se constituiu de articulações teóricas e não pretendeu tratar de pesquisa de campo, o que exigiria abranger a questão metodológica - relatarei dois momentos que vivi nas visitas às escolas ocupadas.

Na primeira dessas instituições, lembro dos estudantes ressaltando o fato de não terem contato com os jovens das escolas particulares do bairro. Propusemos um próximo encontro no qual iríamos chamar os outros jovens, o que foi aceito de pronto. 0 encontro se deu na semana seguinte, com a participação de cerca de 80 secundaristas de três escolas: a estadual pública ocupada e duas escolas particulares, próximas geograficamente. Foi um momento marcante. Inicialmente com predomínio de certa tensão, causada talvez pelas diferenças visíveis, a reunião direcionouse para trocas de facebooks e whatsapps e a promessa de novas ações conjuntas.

Outro exemplo de ausência de submissão nas ocupações foi presenciado no segundo estabelecimento visitado: jovens arrumando a casa para um encontro com a "Clínica do Testemunho" (Projeto criado pela Comissão da Anistia do Ministério da Justiça, visando reparação psíquica e construção de memória dos que sofreram violência do Estado). 0 evento se daria em poucas horas. Eles, alegremente, varriam o chão e limpavam os banheiros como quem oferece uma calorosa hospedagem. A reunião transcorreu com vários testemunhos, inclusive, espontaneamente, com os deles próprios.

Não precisamos, contudo, apostar apenas nesses momentos incomuns como os das escolas ocupadas. Por que não conceber que podem existir, no dia a dia da escola, espaços facilitadores de ações criativas? É aí que penso nos trabalhos desenvolvidos em diálogo com a psicanálise.

As "rodas de conversas" com grupos de crianças, por exemplo, além de poderem auxiliar num cotidiano escolar mais democrático, podem ser um dispositivo que se beneficia de conhecimentos trazidos pela psicanálise. Conhecimentos esses que ajudam os educadores a conceberem que, para ensinar bem, é preciso inquietar a razão e desfazer-se de hábitos típicos do conhecimento que se pretende objetivo. Nessa direção, por que não dizer que educar envolve certa "sedução do bem", na qual se pode despertar ou refinar uma sensibilidade?

As escolas, com seu tempo burocratizado, tendem a engessar as possibilidades de mudanças que, por outro lado, 
a noção psicanalítica de "infantil" afirma. Contudo, a partir dos meus contatos com essas instituições, tenho presenciado alguns momentos em que transformações acontecem. Não há ingenuidade ou credulidade nessas propostas. Há aposta, sem garantias, de que somos - também nos espaços escolares pessoas capazes de nos transformarmos e mudarmos o mundo. Afinal, não estamos todos no mesmo barco da existência?

\section{REFERÊNCIAS BIBLIOGRÁFICAS}

Aragãa, R.0. A importância da formação dos professores da primeira infância. Disponível em: HTTP://www.senado.gov. $\mathrm{br} / \mathrm{sf} / \mathrm{senado/programas/infanciaepaz/artigo.asp.} \mathrm{Acesso}$ em 20 out. 2009.

Birman, J. Arquivos do mal-estar e da resistência. Rio de Janeiro: Civilização Brasileira, 2006.

Ehrenberg, A. La Fatigue d'être-soi - depression et societé. Paris: Odile Jacob, 1998.

Freud, S. (1912). Recomendações aos médicos que exercem a psicanálise. Edição Standard Brasileira das Obras Completas. Rio de Janeiro: Imago, 1977, v. XII.

Freud, S. (1914). Algumas reflexões sobre a psicologia escolar. Op. cit, v. XIII.

Freud, S. (1932). Explicações, aplicações e orientações, Op. cit., v. XXII.

Freud, S. (1921). Psicologia das massas e análise do ego, Op. cit. XVIII.

Fulgencio, L. Notas sobre o interesse da psicologia dinâmica de Winnicott para a educação". In: Aprender: cadernos de filosofia e psicologia da educação. Vitória da Conquista, ano $6, n^{0} 11$, pp. $75-108,2008$.

Kehl, M.R. Existe a função fraterna? In: Kehl. M.R. (Org.). Função fraterna. Rio de Janeiro: Relume Dumará, 2000. 
Kupfer, M.C. O que toca à/a psicologia escolar:

desdobramentos do encontro entre psicanálise e educação.

In: Machado, A.M..; Lerner, A.B.C.; Fonseca, P.F. (Orgs.).

Concepções e proposições em Psicologia e Educação. 2015.

Loparic, Z. Origem em Heiddegger e Winnicott. In: Aprender: cadernos de filosofia e psicologia da educação. Vitória da Conquista, ano 6, n. 11, pp. 15-44, 2008.

Maciel, M.R. A creche e o desenvolvimento infantil: um ambiente suficientemente bom?. In: Psicanálise e educação. São Paulo: Pearson, 2016.

Mariotto, R.M.M. Cuidar, educar e prevenir: as funções da creche na subjetivação de bebês. São Paulo: Escuta, 2009.

Millot, C. Freud: anti-pedagogo. Rio de Janeiro: Zahar, 1987.

Miranda, M.P.; Santiago, A.L.; As conversações e a psicanálise aplicada à educação: um estudo do mal-estar do professor e o aluno considerado problema. In: O declínio dos saberes e o mercado do gozo, 8, 2010. São Paulo: Proceeding online... FE/USP.

Outeiral, J. Trabalho com grupos na escola. In: Outeiral, J.; Cerezer, C. (Orgs.) 0 mal-estar na escola. Rio de Janeiro: Revinter, 2005.

Sennett, R. O declínio do homem público: as tiranias da intimidade. São Paulo: Companhia das letras, 1998.

Winnicott, D. (1963). Moral e Educação. In: O ambiente e os processos de maturação: estudos sobre a teoria do desenvolvimento emocional. Porto Alegre: Artmed, 1983.

Winnicott, D. (1936). Higiene mental da criança pré-escolar. In: Pensando sobre crianças. Porto Alegre: Artes Médicas, 1996.

Recebido: 04/12/2017

Revisto: 09/04/2018

Aceito: 09/04/2018

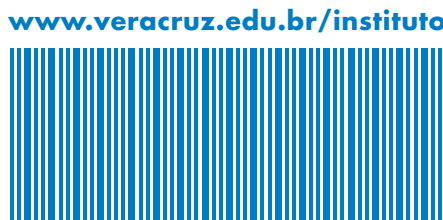

